\title{
Application of a Tritium Imaging Plate Technique to Depth Profiling of Hydrogen in Metals and Determination of Hydrogen Diffusion Coefficients
}

\author{
Teppei Otsuka ${ }^{1, *}$ and Tetsuo Tanabe ${ }^{2}$ \\ ${ }^{1}$ Department of Electric and Electronic Engineering, Faculty of Science and Engineering, Kindai University, \\ Higashi-Osaka 577-8502, Japan \\ ${ }^{2}$ Interdisciplinary Graduate school of Engineering Sciences, Kyushu University, Kasuga 816-8580, Japan
}

\begin{abstract}
A new methodology for depth profiling of hydrogen in metals is developed applying a tritium imaging plate technique (TIPT) with cross sectional observation. Owing to its high sensitivity and wide dynamic range for tritium detection, depth distribution of hydrogen dissolved in the BCC metals such as tungsten (W) and steels are successfully obtained. The depth distributions enable us to determine reliable lattice diffusion coefficients of hydrogen in $\mathrm{W}$ and a ferritic/martensitic steel (F82H) within 20\% errors taking into account three dimensional desorption/ release from the surfaces of the sample metals. Hydrogen trapped at surface and subsurface are clearly separated from the dissolved one. In BCC metals, since the former could be much larger than the latter, observation of overall hydrogen behavior without knowing detailed depth distributions could lead to wrong estimation of diffusion coefficients and solubility. [doi:10.2320/matertrans.M2017175]
\end{abstract}

(Received June 14, 2017; Accepted July 21, 2017; Published September 25, 2017)

Keywords: hydrogen, tritium, tungsten, ferritic steel, imaging plate, depth profile, diffusion coefficient, trapping

\section{Introduction}

Hydrogen $(\mathrm{H})$ diffusion coefficients in metals have been determined mostly by permeation or desorption, owing to easy detection of permeated or desorbed hydrogen. However, permeation and desorption are often disturbed by trapping effects, resulting in significant reduction of apparent diffusion coefficients. The trapping effects are appreciable particularly in BCC metals like iron $(\mathrm{Fe})$ and tungsten $(\mathrm{W})^{1,2)}$ in which $\mathrm{H}$ solubility is much less than that of FCC metals like nickel (Ni). Furthermore, a tiny $\mathrm{H}$ flux permeated or desorbed from the metals surfaces are easily affected by surface impurities like oxygen $(\mathrm{O})$ and carbon $(\mathrm{C})$, which are segregated from bulk or taken from surrounding atmosphere; even $\mathrm{H}_{2}$ gas includes $\mathrm{H}_{2} \mathrm{O}^{3)}$. In order to avoid the effects of trapping and surface impurities, diffusion analysis based on depth distribution would be better compared to those based on $\mathrm{H}$ release.

However, observation of $\mathrm{H}$ depth distribution in metals is quite hard. Although various ion beam techniques give the $\mathrm{H}$ depth distribution, they are limited in near surface region. Only a sectioning method allows us to determine the $\mathrm{H}$ depth distribution, in which a $\mathrm{H}$ loaded sample is sectioned into small pieces parallel to the sample surface toward a depth direction and $\mathrm{H}$ retained in the sectioned pieces is determined by thermal desorption or other $\mathrm{H}$ detection techniques. Several problems still remain in the sectioning method; time consuming for the sectioning process accompanying possible $\mathrm{H}$ release, difficulty of detection of small amount of $\mathrm{H}$, and very poor depth resolution. Applying a tritium $(\mathrm{T})$ tracer technique, diffusional behaviors of $\mathrm{T}$ diluted in $\mathrm{H}$ in hydride forming metals have been investigated by the sectioning method ${ }^{4,5)}$. However, metals which absorb $\mathrm{H}$ endothermically, such as Fe and W (referred as endothermic $\mathrm{H}$ occluders, hereafter) having very low solubility, were quite hard to observe the $\mathrm{H}$ depth distribution by the

*Corresponding author, E-mail: teppei.otsuka@ele.kindai.ac.jp time-consuming sectioning method.

In previous studies, we have applied a tritium imaging plate technique (TIPT) to get $\mathrm{H}$ depth distributions in $\mathrm{mm}$ to $\mathrm{cm}$ scale in depth with a depth resolution of several tens $\mu \mathrm{m}$ by a cross-sectioning method. In this method, a T loaded sample was bisected perpendicular to the loaded surface to appear a cross-sectional surface and an areal $\mathrm{T}$ distribution on the surface ( $\mathrm{T}$ profile) was observed by TIPT. With this method, we have succeeded to get reliable depth distributions of $\mathrm{H}(\mathrm{T})$ loaded in hydride forming metals like zirconium and vanadium alloys ${ }^{6-10)}$. In the present study, we have established TIPT to observe T surface profile and depth distribution with the cross-sectioning method and successfully applied to investigate solution, trapping, diffusion and desorption/permeation behaviors of $\mathrm{H}$ in endothermic hydrogen occluders of pure $\mathrm{W}^{11)}$ and a ferritic/martensitic steel ${ }^{12,13)}$ which are candidates of plasma facing wall and/or a structure in a nuclear fusion reactor.

\section{Principle of Tritium Imaging Plate Technique (TIPT)}

Quantification of the absolute amount of $\mathrm{T}$ in metals by radiation measurements is not easy because energy of emitted electrons by $\beta$-decay of $\mathrm{T}$ (hereinafter referred as $\mathrm{T}$ $\beta$-electrons) is too low to pass through materials (even in air) in a long distance. TIPT is a good method to detect T existing on metal's surface and have been used for surface profiling of T. Nevertheless, to quantify $\mathrm{T}$ concentration with the detection of the $\mathrm{T} \beta$-electrons by TIPT, their energy loss during passing through materials before coming in a detector (IP) should be taken into account.

This section describes how the $\mathrm{T} \beta$-electrons lose their energy during passing through a metal and deposit their remaining energy on IP attached to the surface of the metal.

\subsection{Detection of $\beta$-electrons emitted from the surface of metals retaining $\mathbf{T}$}

When an electron having energy $\epsilon$ is emitted by $\beta$-decay 
of a $\mathrm{T}$ atom in a material and travels in it to the $\mathrm{z}$ direction, it loses energy as,

$$
-\frac{\partial \epsilon}{\partial z}=S(\epsilon)
$$

where $S(\epsilon)$ is referred as a stopping power $\left(\mathrm{eV} \cdot \mathrm{m}^{-1}\right)$, which is determined experimentally and/or theoretically. When the electron comes up to the surface after travelling distance $z$ in a material with its initial energy $\epsilon_{0}$, its energy is reduced to

$$
\epsilon(z)=\epsilon_{0}-\int_{0}^{z}(S(\epsilon)) d z .
$$

The energy of the $\beta$-electron ranges from 0 to $18.6 \mathrm{keV}$ with the average of $5.7 \mathrm{keV}$. When T atoms are distributed in depth with their areal density of $\rho(z)$, they emit $\beta$-electrons with areal energy density of $\epsilon \lambda \rho(z)$ in a unit time. Here $\lambda$ $\left(\mathrm{s}^{-1}\right)$ is the disintegration constant of $\mathrm{T}$. Then energy flux carried by escaping electrons from the surface is given by,

$$
\epsilon=\int_{0}^{z} \int_{0}^{18.6 \mathrm{keV}}\left(\epsilon_{0}-\int_{0}^{z}(S(\epsilon))\right) \lambda \rho(z) d \epsilon \mathrm{dz} .
$$

When an imaging plate (IP) made of a plastic substrate coated with phosphor layers $\left(\mathrm{BaFBr}: \mathrm{Eu}^{2+}\right)$ contacts to the surface of the metal retaining $\mathrm{T}$ for a certain time duration, all emitted energy given by eq. (3) is absorbed (deposited) in the phosphor layers, since their thickness is enough to stop all electrons escaping from the surface. Certain parts of the deposited energy in IP is used to excite electrons in the phosphors from the ground state to an quasi-stable exited state $^{14)}$. When the excited electrons are further excited to a little higher energy level by violet photons, they are relaxed with photon emission referred as Photo-Stimulated Luminescence (PSL). An IP reader makes this process to give digitized PSL intensity from IP exposed to a T retaining sample. The PSL intensity shows a good linear relationship with the deposited energy in IP over five orders of magnitude. Then the deposited energy profile determined from the PSL intensity profile is correlated to a $\mathrm{T}$ depth distribution, $\rho(\mathrm{z})$, in the metal according to eq. (3). It should be noted that some of the electrons in the quasi-stable excited state are thermally relaxed, resulting in fading phenomena, i.e. loss of the reliability. Therefore, IP measurements should be conducted at lower temperatures than room temperature (RT) and the PSL intensity must be read immediately after the exposure of IP to radiation sources or some correction for the fading is required for absolute $\mathrm{T}$ activity measurements.

Equation (3) is one-dimensional analysis or assuming a uniform areal $\mathrm{T}$ density in a plane perpendicular to the depth direction. In case the areal $\mathrm{T}$ density is not uniform, energy losses caused by three-dimensional electron transport in a metal should be taken into account. However, owing to the short escaping depth of the $\mathrm{T} \beta$-electrons, the inhomogeneity of the areal $\mathrm{T}$ density within the length equivalent to the projected range of the $\mathrm{T} \beta$-electrons in the metal (within a few $\mu \mathrm{m})$ is hardly observed. In other words, an areal PSL intensity distribution (referred as an IP image hereafter) does not reflect the areal (planar) inhomogeneity within the projected range. Since the range is shorter than the width of one pixel (the minimum detection area) of IP, around $25 \mu \mathrm{m}$, the IP image projects well areal inhomogeneity over $25 \mu \mathrm{m}$ i.e. the space resolution of IP. In the stopping power, energy losses due to photon emissions, such as characteristic X-rays, Bremsstrahlung and other secondary photons are included. Although IP detects energy deposition by both electrons and photons, more than $90 \%$ of energy deposited in IP is given by the electrons (including primary $\beta$-electrons and secondary electrons). Hence, the effects caused by the photon emission on IP were neglected in the present work. If a shielding film with its thickness enough to shield the electrons and to allow penetration of the photons is placed between a sample metal and IP, detection of $\mathrm{T}$ in deeper region is possible ${ }^{15)}$. This is realized as BIXS (Beta ray Induced X-ray Spectrometry) ${ }^{16)}$.

\subsection{Quantification of $\mathbf{T}$ at a surface and in subsurface and bulk of metals}

As described above, the advantage of TIPT is to give areal $\mathrm{T}$ profiles. According to eq. (3), in principle, an IP image can be converted to the absolute amount of deposited energy profiles taking various corrections, such as fading, and depth distributions of $\mathrm{T}$ in a metal, into account.

In case, $\mathrm{T}$ is uniformly dissolved in a metal, its $\mathrm{T}$ activity can be determined considering the fading only. $\mathrm{H}$ including $\mathrm{T}, \mathrm{H}(\mathrm{T})$, once dissolved in exothermic $\mathrm{H}$ occluders, i.e. hydride forming metals, like zirconium $(\mathrm{Zr})$ is not easily released and its dissolved amount is far larger than that in the endothermic $\mathrm{H}$ occluders by several orders of magnitude. Two insets of Fig. 1 shows surface $\mathrm{T}$ profiles of the $\mathrm{Zr}$ disk samples dissolving $\mathrm{H}$ (including $\mathrm{T}$ with $\mathrm{T} / \mathrm{H}=1.2 \times 10^{-6}$ ) homogeneously with 2300 and 4600 appm. The averaged $\mathrm{T}$ intensity over the whole sample surface area is plotted against the $\mathrm{H}$ concentration in Fig. 1. A good linear relationship starting from the origin is found in the figure. Assuming that the $\mathrm{T}$ concentration against $\mathrm{H}$ in $\mathrm{Zr}$ is same as that in the loading gas, the concentration of $\mathrm{T}$ dissolved homogeneously in $\mathrm{Zr}$ can be determined. This is used for quantitative determination of $\mathrm{T}$ concentration by TIPT and referred as the master curve method.

Since the projected range of the $\mathrm{T} \beta$-electron is less than a few $\mu \mathrm{m}$ in most of solid metals, detection of $\mathrm{T}$ located at a

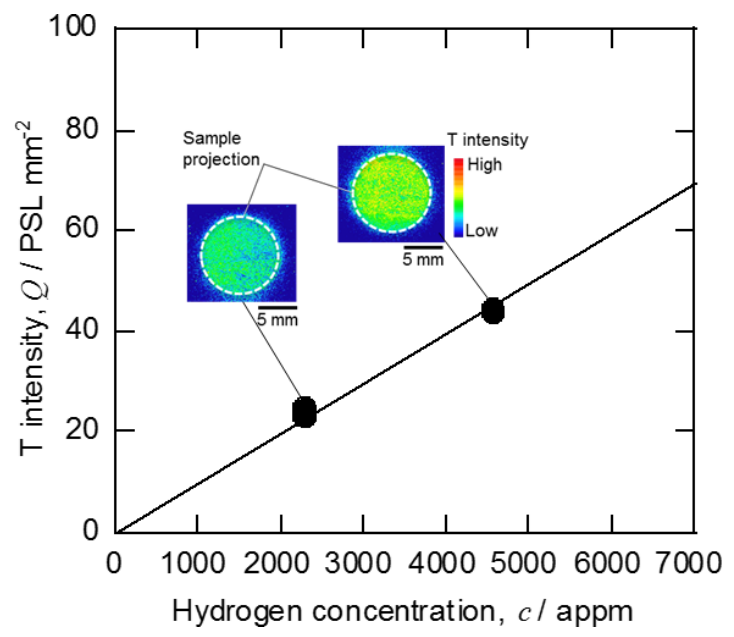

Fig. 1 Relationship between $\mathrm{H}$ concentration and $\mathrm{T}$ intensity for $\mathrm{Zr}$ dissolving $\mathrm{H}$ (including $\mathrm{T}$ with $\mathrm{T} / \mathrm{H}=1.2 \times 10^{-6}$ ) homogeneously with 2300 and 4600 appm. 
depth beyond a few $\mu \mathrm{m}$ is hardly possible. In other words, the deposited energy in IP measured as PSL intensity corresponds to deposited energy of all electrons and photons escaping from the surface of the metals and surrounding materials. Therefore, an IP image shows an areal intensity distribution of $\mathrm{T}$ existing in surface region within a few $\mu \mathrm{m}$ in depth and with a few $\mu \mathrm{m}$ areal resolution. Hereinafter, the areal PSL intensity distribution evaluated by IP is referred as a surface $\mathrm{T}$ profile.

According to eq. (3), deconvolution of the deposited energy in IP makes non-destructive depth profiling of T possible within a few $\mu \mathrm{m}$, the range of the $\mathrm{T} \beta$-electron. To do this, a film insertion technique is used as shown in Fig. 2. Electrons escaping from the surface are screened by the inserted film, depending on their energies. Changing the thickness of the inserted film, IP measurements are repeated. Considering all the geometries and the stopping powers of the metal retaining $\mathrm{T}$, the inserted film and IP, the deposited energy in IP given by eq. (3) is calculated with Monte-Carlo simulation program codes. By fitting the calculated results to the experimental ones, the areal $\mathrm{T}$ density in depth can be determined. This method has been verified to give the reliable depth distribution of $\mathrm{T}$ concentration in carbon materials by Sugiyama et al. $^{17)}$

\section{Experimental}

\subsection{Samples}

The samples used were FCC metals of pure copper $(\mathrm{Cu})$ and pure nickel $(\mathrm{Ni})$, and $\mathrm{BCC}$ metals of pure iron $(\mathrm{Fe})$, pure molybdenum (Mo) and pure tungsten (W). Nominal purities of them were above 99.8 mass\% except for $\mathrm{W}$ which was powder-metallurgical polycrystalline $\mathrm{W}$ with the nominal purity of 99.99 mass\% (procured from A.L.M.T. Corp.). A ferritic/martensitic stainless steel $(\mathrm{F} 82 \mathrm{H})$ was also examined for a future application as first wall of fusion devices. The chemical compositions of the $\mathrm{F} 82 \mathrm{H}$ steel were described elsewhere ${ }^{18)}$; main elements are 8 mass $\% \mathrm{Cr}, 2$ mass $\% \mathrm{~W}$ and balanced Fe. Details of a shape and a size of the sample were described in the following section.

\subsection{Hydrogen and tritium loading}

$\mathrm{H}(\mathrm{T})$ was loaded to the samples either by a gas absorption method or by a glow discharge method. Initial H(T) distributions were set to be homogeneous for the gas absorption, while only surface loaded for the glow discharge.

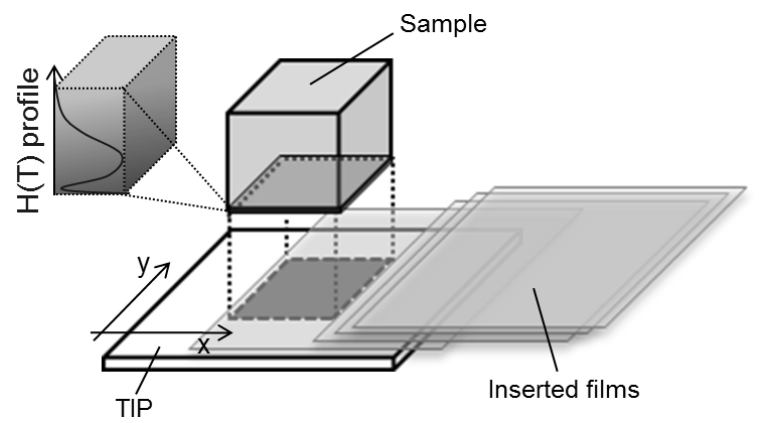

Fig. 2 Schematic of depth profiling of T by the film insertion method with using TIPT.
The gas absorption method with $\mathrm{H}_{2}$ gas of $13.3 \mathrm{kPa}$ and at $873 \mathrm{~K}$ for $1 \mathrm{~h}$ was conducted for sample sheets of $\mathrm{Cu}, \mathrm{Ni}, \mathrm{Fe}$ and Mo $(10 \mathrm{~mm} \times 10 \mathrm{~mm} \times 0.1 \mathrm{~mm})$ to establish homogeneous $\mathrm{H}(\mathrm{T})$ distribution in the whole sample volume. The $\mathrm{H}_{2}$ gas contained $\mathrm{T}$ with $\mathrm{T} / \mathrm{H}=1.2 \times 10^{-6}$. To observe a depth profile in near surface region of $\mathrm{Cu}$ by the film insertion method, another $\mathrm{H}(\mathrm{T})$ loading was conducted with a higher $\mathrm{T}$ concentration of $\mathrm{T} / \mathrm{H}=1.4 \times 10^{-4}$.

In order to observe diffusion process in metals, $\mathrm{H}(\mathrm{T})$ surface loading with a glow discharge method was conducted at one edge surface of a rod-shaped sample. A cube $(6 \times 6 \times$ $\left.6 \mathrm{~mm}^{3}\right)$ of $\mathrm{F} 82 \mathrm{H}$ and a disk $(\phi 25.6 \mathrm{~mm} \times 3 \mathrm{~mm}$ in thickness) of pure $\mathrm{W}$ were exposed to a direct current glow discharged (DCGD) plasma in a limited area at one of their side surfaces through a hole $(\phi 5 \mathrm{~mm})$ of molybdenum mask as schematically shown in Fig. 3. The temperature of the sample was kept constant during DCGD between $298 \mathrm{~K}$ to $674 \mathrm{~K}$. DCGD was carried out with $400 \mathrm{~V}$ in voltage under $\mathrm{H}(\mathrm{T})$ gas pressure of $62 \mathrm{~Pa}\left(\mathrm{~T} / \mathrm{H}=1.4 \times 10^{-4}\right)$. After the loading, the sample was cooled down to RT with a rate of about $1 \mathrm{~K} \mathrm{~s}^{-1}$ by water-quenching of the outside of the discharge vessel to inhibit $\mathrm{H}$ diffusion after the loading.

\subsection{Surface and depth profiling of $T$ retained in metals}

The IP measurements of the loaded surfaces of the $\mathrm{Cu}, \mathrm{Ni}$, $\mathrm{Fe}$ and Mo samples were conducted for $1 \mathrm{~h}$ or $2 \mathrm{~h}$ at RT in a light-tight container to obtain surface $\mathrm{T}$ profiles. Depth profiling of $\mathrm{T}$ near the surface region was conducted for the $\mathrm{Cu}$ sample by the film-insertion method described in Sec. 2 .

After the surface profiling of $\mathrm{T}$, the sample was bisected perpendicular to the $\mathrm{H}(\mathrm{T})$ loaded surface using a diamond-wire saw in a ventilated glove box and finished within a few hours at RT. The T profiles of the cross-sectional surface of $\mathrm{F} 82 \mathrm{H}$ and $\mathrm{W}$ were determined by the IP measurement for $24 \mathrm{~h}$ at a temperature of liquid $\mathrm{N}_{2}$ or below $273 \mathrm{~K}$ in a refrigerator. During the IP measurement, all sample surfaces were shielded to avoid the $\mathrm{T} \beta$-electrons getting in from other surfaces than the measured cross-sectional surface. This method to get the $\mathrm{T}$ depth distribution is referred as a cross-sectioning method, hereafter.

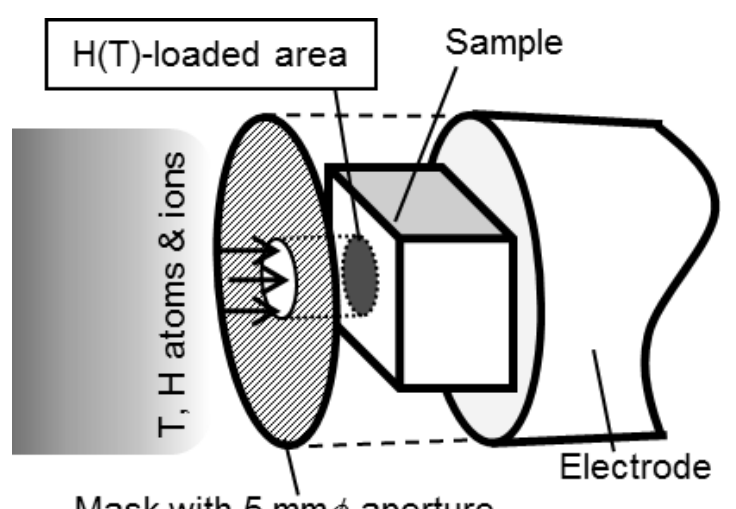

Mask with $5 \mathrm{~mm} \phi$ aperture

Fig. 3 Schematic of $\mathrm{T}$ loading by plasma discharge. 


\section{Results}

\subsection{Surface $\mathrm{T}$ distribution of pure $\mathrm{Cu}, \mathrm{Ni}, \mathrm{Fe}$ and $\mathrm{Mo}$}

In Fig. 4(a), surface photographs and $\mathrm{T}$ profiles for all samples are compared in the same geometrical scale. In the $\mathrm{T}$ profiles, relative $\mathrm{T}$ intensity is higher as their colors change from blue, yellow and green to red. One can see that the $\mathrm{T}$ profiles are quite inhomogeneous with localized high intensity area appeared as small spots all over the surfaces and lines near the edges of the samples. $\mathrm{T}$ intensities were averaged over the whole sample surface area and compared with $\mathrm{H}$ concentrations calculated with using the reported $\mathrm{H}$ solubility of respective metals ${ }^{19-21)}$ under the present $\mathrm{H}$ loading condition in Fig. 4(b). There is no correlation between the $\mathrm{T}$ intensities and the $\mathrm{H}$ concentrations at all. The $\mathrm{T}$ intensity of $\mathrm{Cu}$ was highest, while its $\mathrm{H}$ solubility the smallest, i.e. one tens less than that of Ni. This indicates that $\mathrm{T}$ observed by TIPT is decoupled from $\mathrm{T}$ dissolved in bulk, in other words, most of $\mathrm{T}$ observed on the $\mathrm{Cu}$ surface is very likely localized at its surface and/or subsurface but not in the bulk.

Figure 5(a) shows $\mathrm{T}$ depth distribution within a detectable depth of the sample determined by the film insertion method. In the figure, the $\mathrm{T}$ intensity averaged over the whole surface area are plotted against the thickness of the inserted film for eight different thicknesses. The insets in the figure are observed surface $\mathrm{T}$ profiles for four different thicknesses.Employing reported values of the stopping powers of electrons in $\mathrm{Cu}$ and the inserted films, the deposited energy in IP for the $\mathrm{T} \beta$-electrons emitted in $\mathrm{Cu}$ and passed through the inserted films were calculated by a Monte-Carlo simulation code (PHITS 2.64, Japan Atomic Energy Agency $\left.{ }^{22)}\right)$. In the calculation, compositions of the materials are chosen as $\left(-\left(\mathrm{C}_{6} \mathrm{H}_{5}\right)-\mathrm{S}-\right)$ for the inserted film, BaFBr for the phosphor in IP and pure $\mathrm{Cu}$, and their densities were $1.35,4.51$ and $8.94 \mathrm{~g} \mathrm{~cm}^{-3}$, respectively. The thickness of the phosphor in IP was $50 \mu \mathrm{m}$. The energy profile of the T $\beta$-electrons was given in the literature ${ }^{23)}$. The cut-off energy employed in the calculation was $1 \mathrm{keV}$. In Fig. 5(a), deposited energies in IP thus calculated were given for two extreme cases, (1) $\mathrm{T}$ is fully localized at the top surface given as a dashed line, (2) $\mathrm{T}$ is uniformly distributed in $\mathrm{Cu}$ given as a dotted line (see also Fig. 5(b)). As clearly seen in the figure, the observed data are between the two but closer to the latter case (the dotted line) than the former case (the dashed line). This indicates depletion of $\mathrm{T}$ in the shallower region from the uniform distribution (except the top surface) in the actual $\mathrm{T}$ depth profile.

As described in Sec. 2, the deposited energy plotted against the inserted film thickness can be deconvoluted to a $\mathrm{T}$ depth distribution. Black dots and line (3) in Fig. 5(b) show the T depth distribution within $1 \mu \mathrm{m}$ thus determined. Lines (1) and (2) in the figure correspond to the two extreme cases in the depth profile discussed above. The T depth profile thus obtained is convoluted into the $\mathrm{T}$ intensity profile against the thickness of the inserted films. The result is given as the solid line in Fig. 5(a) and reproduces the experimental data quite well. The $\mathrm{T}$ depth distribution in Fig. 5(b) indicates that $\mathrm{T}$ was highly localized near the top surface, significantly depressed within $0.6 \mu \mathrm{m}$, and restored a little to a homogeneous level in the deeper region. Because of the limited range of the $\mathrm{T} \beta$-electrons, the $\mathrm{T}$ distribution beyond $1 \mu \mathrm{m}$ in depth could not be determined. Nevertheless, the decaying distribution from the deep inside to the top surface is quite natural, suggesting diffusive release of homogeneously dissolved hydrogen in the bulk. The surface localized component should be separated from the diffusional component. The cause could be attributed to surface adsorption of some molecules including hydrogen like $\mathrm{H}_{2} \mathrm{O}$, or trapping at surface defects and/or impurities like surface oxides.

\subsection{Depth distribution of $T$ with a concentration gradi- ent in bulk of $\mathrm{F82H}$ and $W$}

It is generally quite difficult to determine $\mathrm{H}$ depth distributions in endothermic $\mathrm{H}$ occluders, because their $\mathrm{H}$ solubility is quite small. As noted above, however, quite high sensitivity and wider dynamic range in detection of $\mathrm{T}$ by TIPT compared to other $\mathrm{H}$ detection methods allow depth profiling of $\mathrm{T}$ in them. In the following, we have observed $\mathrm{T}$ depth distribution by the cross-sectioning method to investigate $\mathrm{H}$ behaviors in $\mathrm{F}_{82} \mathrm{H}^{12,13)}$ and pure $\mathrm{W}^{11)}$.

Figures 6 (a) and (b) respectively show $\mathrm{T}$ profiles of asloaded surface and the cross-sectional surface together with schematics of TIPT procedures (Sec. 3.3). The T intensity of the as loaded surface shows two levels with higher density in the central area, while that on the cross-section (Fig. 7(b)) gradual change. The cause of the two levels profile of the as loaded surface is attributed to $\mathrm{T}$ trapping at deposited materials (impurities) on a central area owing to a hollow profile in a DCGD column which cause deposition at the central area, while erosion at surrounding area ${ }^{24)}$. Figure 6 (b) clearly shows that $\mathrm{T}$ diffused into bulk from the loaded surface to all other surfaces of the cube.

Figure 7 shows a $\mathrm{T}$ depth distribution along the central axis of the F82H cube just after the loading for $1 \mathrm{~h}$ at $573 \mathrm{~K}$. The $\mathrm{T}$ intensity was highest at around $0.8 \mathrm{~mm}$ in depth without showing the surface accumulation as observed in $\mathrm{Cu}$ (Fig. 5(b)). The surface peak caused by surface absorption and/or trapping was hindered by quite high hydrogen concentration in $\mathrm{F} 82 \mathrm{H}$ loaded by the plasma discharge. Accordingly the depth distribution decayed towards both directions of the loaded surface and the other side surface. The cause of the decay is attributed to diffusional release of $\mathrm{T}$ owing to larger hydrogen diffusion coefficients in $\mathrm{F} 82 \mathrm{H}$. Determination of hydrogen diffusion coefficients form the depth distribution in $\mathrm{F} 82 \mathrm{H}$ is described later.

Figures 8 (a) and (b) show the T depth distributions in the $\mathrm{W}$ disks loaded at $473 \mathrm{~K}$ and $773 \mathrm{~K}$, respectively. The $\mathrm{T}$ intensity was very high at the loaded surface, and followed by sharp decay, 3 orders of magnitude, within $1 \mathrm{~mm}$ in depth. Beyond $1 \mathrm{~mm}$, the decay became more gradual. The loading at higher temperature, $773 \mathrm{~K}$, shows deeper penetration than that at lower temperature and $\mathrm{T}$ reached even to the back surface indicating permeation. Similar to the front surface, significant amount of $\mathrm{T}$ was trapped at the back surface. 
(a)

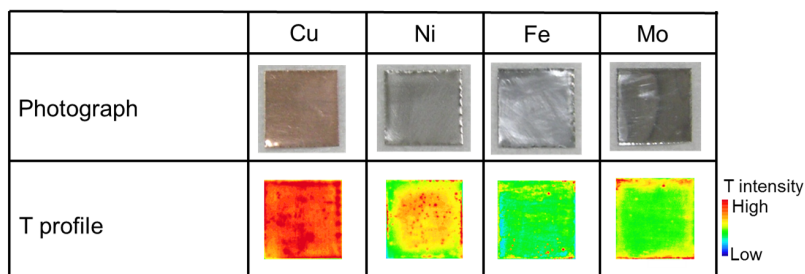

(b)

\begin{tabular}{|l|c|c|c|c|}
\hline $\begin{array}{l}\text { Surface T intensity } \\
{\left[10^{3} \mathrm{PSL} \mathrm{mm} \mathrm{mm}^{-2}\right]}\end{array}$ & 2.4 & 0.8 & 1.1 & 0.7 \\
\hline $\begin{array}{l}\mathrm{H} \text { conc. [appm] } \\
\text { at } 13.3 \mathrm{kPa}, 873 \mathrm{~K}\end{array}$ & 7.6 & 31 & 100 & 24 \\
\hline
\end{tabular}

Fig. 4 (a) Surface photographs and $\mathrm{T}$ profiles determined by TIPT for pure $\mathrm{Cu}, \mathrm{Ni}, \mathrm{Fe}$ and $\mathrm{Mo}$ after the $\mathrm{T}$ loading with using $\mathrm{H}_{2}$ gas including $\mathrm{T}\left(\mathrm{T} / \mathrm{H}=1.2 \times 10^{-6}\right)$ at $13.3 \mathrm{kPa}, 873 \mathrm{~K}$ for $1 \mathrm{~h}$. (b) Averaged $\mathrm{T}$ intensities obtained from $\mathrm{T}$ profiles in Fig. 2 and equilibrium $\mathrm{H}$ concentration given by $\mathrm{H}$ solubility of respective metals under $\mathrm{H}_{2}$ gas at $13.3 \mathrm{kPa}$ and $873 \mathrm{~K}$.

(a)

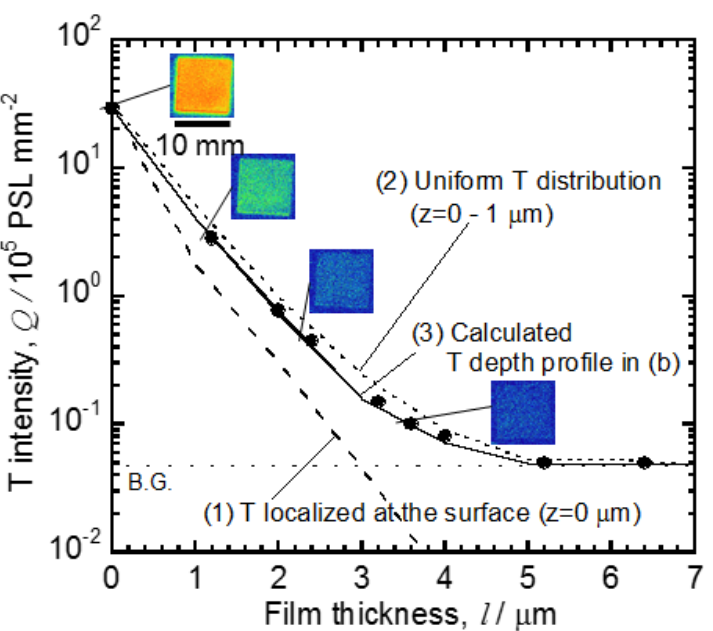

(b)

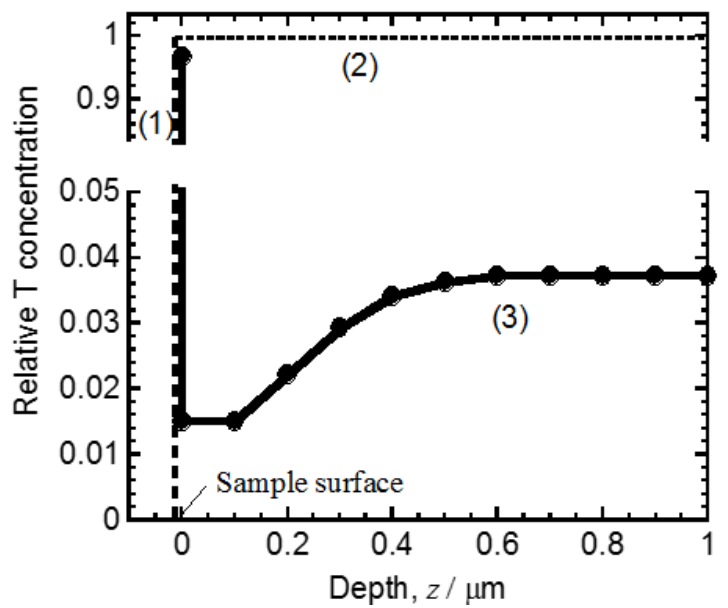

Fig. 5 (a) Dependence of $\mathrm{T}$ intensity determined by TIPT on inserted film thickness for a $\mathrm{Cu}$ sample with $\mathrm{T}$ loaded by the gas absorption method at $873 \mathrm{~K}$ for $5 \mathrm{~h}$. Insets are surface $\mathrm{T}$ profiles obtained with insertion of four different thickness films. Dashed line (1), dotted line (2) and solid line (3) are theoretical relations corresponding to depth profiles given in (b), (b) Depth profiles; (1) T localized at the surface, (2) T dissolved homogenously in whole thickness, and (3) T profile determined by deconvolution of eq. (3) showing the best fit to the observed dependence (See text). (a)

(b)


Fig. 6 Areal distributions of T loaded at $373 \mathrm{~K}$ for $3 \mathrm{~h}$ to $\mathrm{F} 82 \mathrm{H}$ steel by DCGD plasma on (a) the loaded surface and (b) the cross-sectional surface.

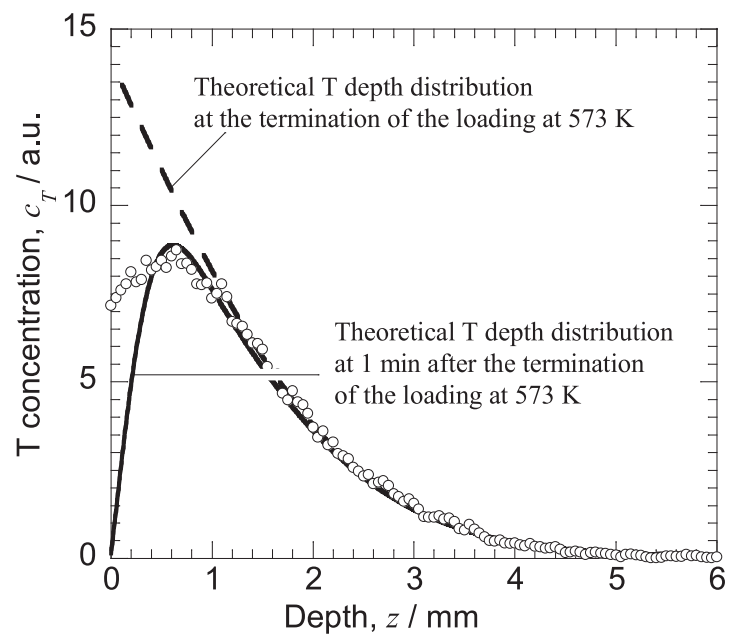

Fig. 7 Observed $\mathrm{T}$ depth distribution in F82H after the loading at $573 \mathrm{~K}$ for $1 \mathrm{~h}$. Dashed and solid lines are theoretical distributions at the termination of the loading at $573 \mathrm{~K}$, and $1 \mathrm{~min}$ after the termination, assuming both dissolution during the loading and release after the termination of the loading are controlled by simple diffusion at $573 \mathrm{~K}$.

\section{Discussion}

\subsection{Determination of hydrogen diffusion coefficients from depth distributions in the endothermic $\mathbf{H}$ occluders}

It should be noted that TIPT gives profiles of $\mathrm{T}$ diluted in $\mathrm{H}$ but not pure $\mathrm{H}$ nor $\mathrm{T}$. Nevertheless, the $\mathrm{T}$ profile reflects the $\mathrm{H}$ profile within errors caused by mass difference of $\mathrm{H}$ and T, i.e. isotopic effects. In a following section, we have used the term of "depth distribution of $\mathrm{H}$ concentration (simply as $\mathrm{H}$ depth distribution)" instead of "depth distribution of concentration of $\mathrm{T}$ diluted in $\mathrm{H}$ " and "diffusion coefficients of H" instead of "diffusion coefficient of T diluted in $\mathrm{H}$ " and discussed $\mathrm{H}$ behavior instead of behavior of $\mathrm{T}$ diluted in $\mathrm{H}$, allowing errors caused by the isotopic effects $(\sim \sqrt{3})$. That is 

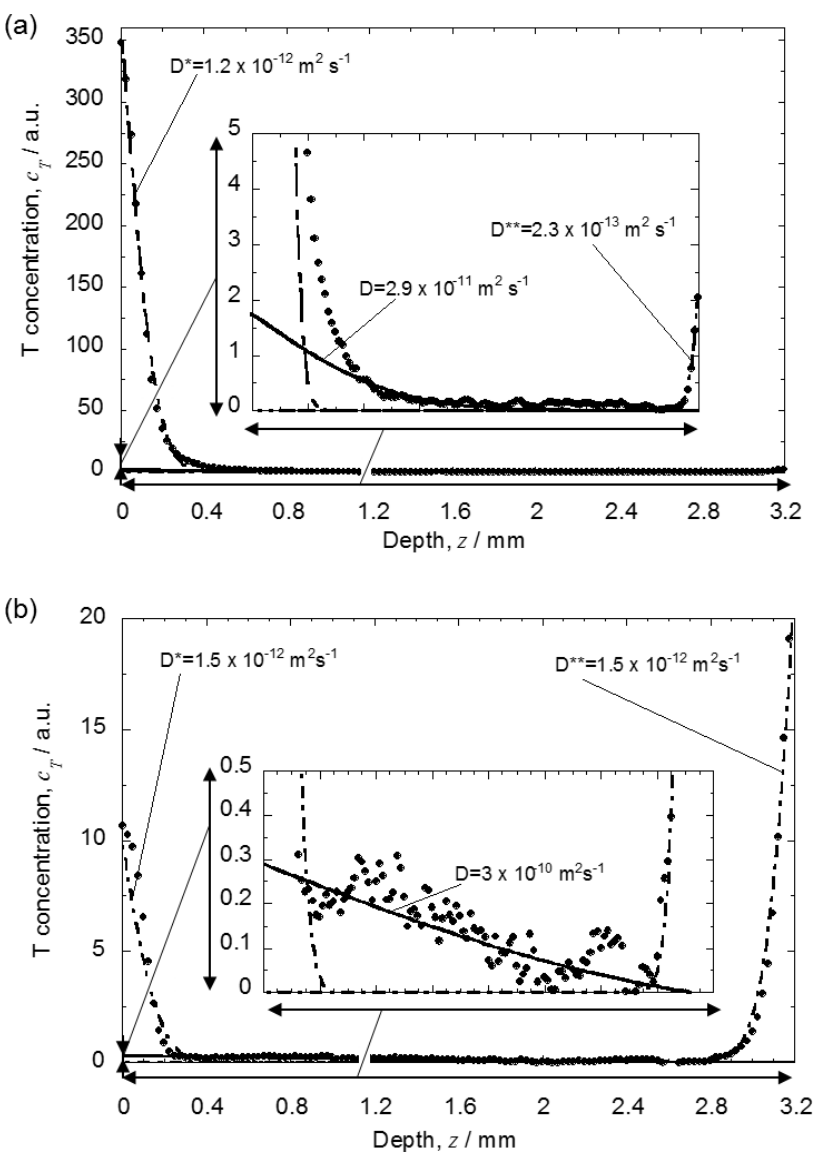

Fig. 8 T depth distributions in pure $\mathrm{W}$ just after the loading by plasma discharge at (a) $473 \mathrm{~K}$ and (b) $773 \mathrm{~K}$ for $2 \mathrm{~h}$. Insets are enlarged in vertical axis and shortened in horizontal axis to make the depth distribution near surface clearer. Diffusion coefficients given in the figures are determined by data fitting (see text).

because temperature dependence of diffusion coefficients of $\mathrm{H}$ in most metals usually includes large errors caused by data scattering, and accordingly the errors coming from the isotopic effects are mostly within the experimental errors of the present work. In this section, $\mathrm{H}$ diffusion coefficients in $\mathrm{F} 82 \mathrm{H}$ and $\mathrm{W}$ were determined from the $\mathrm{T}$ depth distributions and the validity of the obtained data was discussed in comparison with the literature data.

$\mathrm{H}$ concentration at the loaded surface was constant during the loading since an $\mathrm{H}$ influx from plasma and a release flux from the loaded surface were balanced in a steady-state condition. Therefore, we selected surface concentration constant as the boundary condition in following diffusion analysis of $\mathrm{H}$ loaded by plasma discharge.

Since $\mathrm{T}$ diffuses three dimensionally (3d) as appeared in Fig. 6 (b), one dimensional (1d) analysis from the cross-sectional surface could have certain error. Therefore, verification of the $1 \mathrm{~d}$ diffusion analysis for a cube $(10 \times 10 \times$ $10 \mathrm{~mm}^{3}$ ) with $\mathrm{H}$ loaded by discharge was made. Assuming that $\mathrm{H}$ concentration is zero at all cube surfaces except for the loaded one where the $\mathrm{H}$ concentration is kept constant during the loading, $\mathrm{H}$ concentration in the cube, $c(x, y, z)$, was determined by numerically solving $3 \mathrm{~d}$ Fick's diffusion equation using $\mathrm{H}$ diffusion coefficient of $1 \times 10^{-11} \mathrm{~m}^{2} \mathrm{~s}^{-1}$ for a diffusion time of $2 \mathrm{~h}$ at $473 \mathrm{~K}$ as in the case for pure W. Figure 9(a) shows a profile of the $\mathrm{H}$ concentrations on the
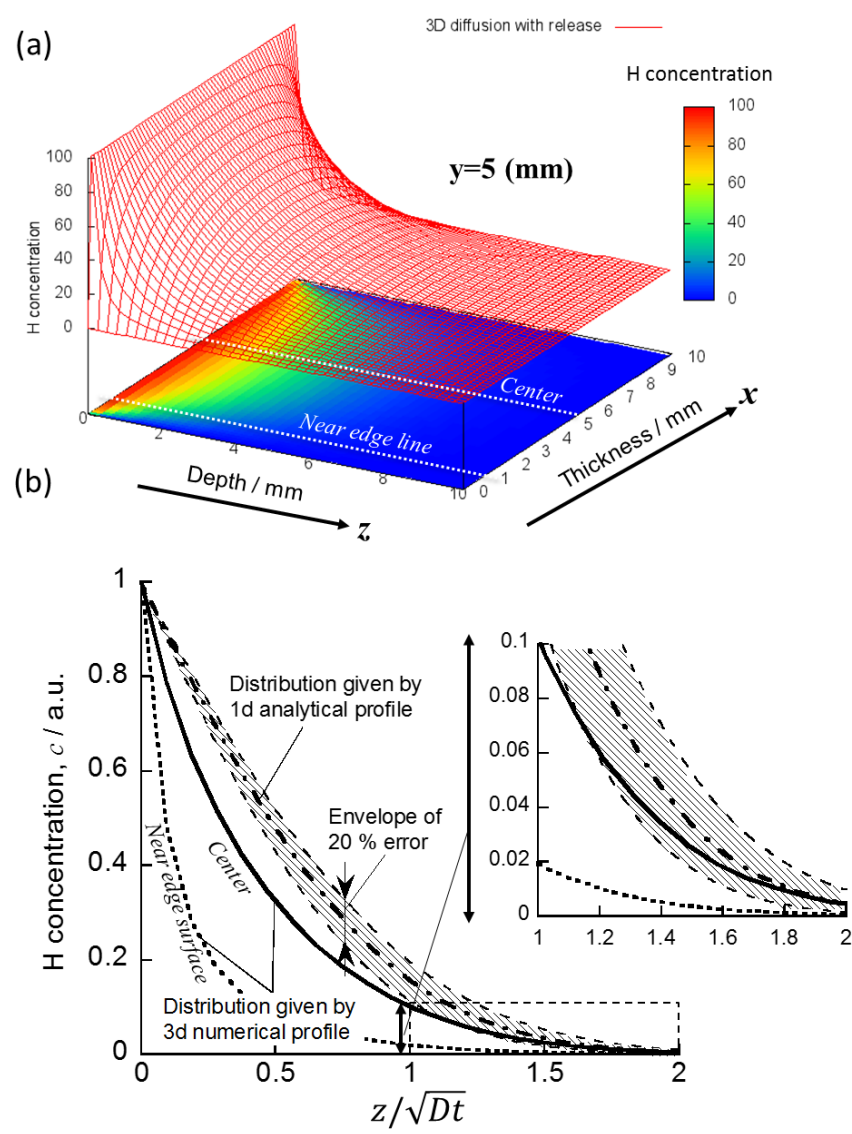

Fig. 9 (a) Calculated $\mathrm{H}$ distribution on the central plane, $\mathrm{c}(\mathrm{x}, 5, \mathrm{z})$ in a cube $\left(10 \times 10 \times 10 \mathrm{~mm}^{3}\right)$ with $\mathrm{H}$ loading at one side surface $(\mathrm{z}=0)$ which is shown as contours and areal colour profile, (b) $\mathrm{H}$ depth distributions along the central axis $\mathrm{x}=5$ (bold line) and a near edge line $\mathrm{x}=$ 0.5 (dotted line). A depth distribution given by $1 \mathrm{~d}$ analysis (dashed and dotted line) with envelopes of $20 \%$ error is also given for comparison.

central plane of the cube, $c(x, 5, z)$, as contours and planer projection with colors changing from red, yellow, green and blue corresponding to higher to lower concentrations. The figure clearly shows concentration decays towards all side surfaces, indicating diffusional release from the all surfaces. The $\mathrm{H}$ depth distributions along the central axis, $x=5$, and a near edge line, $x=0.5$ indicated in Fig. 9(a) are shown in Fig. 9(b) in which $z$ axis is converted to the normalized diffusion length $(z / \sqrt{D t})$. In the figure, an analytical solution of 1d Fick's equation given below is also plotted for comparison,

$$
c(z)=c_{0} \operatorname{erfc}\left(\frac{z}{2 \sqrt{D t}}\right),
$$

where $c_{0}$ is the constant $\mathrm{H}$ concentration at the loaded surface during the loading and $D$ is an $\mathrm{H}$ diffusion coefficient. Although the $1 \mathrm{~d}$ analytical solution deviates from the $3 \mathrm{~d}$ numerical solution in shallower region, the former becomes closer to the latter in deeper region and the latter lies within the envelope of $20 \%$ errors of the former as depicted in the enlarged inset of Fig. 9(b). In deeper region, or with increasing the depth (thickness perpendicular to the loaded surface) the error becomes less. Considering the geometry of the present samples, the values of $D$ determined with the $1 \mathrm{~d}$ analysis given below have errors less than $20 \%$ error. Note that release of $\mathrm{H}$ after the loading and during a cooling could 
also change $\mathrm{H}$ depth distributions, which is discussed in sections of 5.1.1 and 5.2.

\subsubsection{H diffusion coefficients in $\mathbf{F 8 2 H}$}

Although $\mathrm{H}$ diffusion coefficients determined by the $1 \mathrm{~d}$ diffusion analysis of the $\mathrm{T}$ depth distribution obtained from the cross-sectioning method include some errors as discussed above, the analysis using the $\mathrm{T}$ depth distribution limited for deeper region reduces the error. In the following, $\mathrm{H}$ diffusion coefficients are determined from the $1 \mathrm{~d}$ analysis of the T depth distributions obtained by TIPT for more than $1 \mathrm{~mm}$ deeper region. Accordingly, the error would be much less than $20 \%$ as depicted in Fig. 9(b).

Figure 10 shows thus determined $\mathrm{H}$ diffusion coefficients from the $\mathrm{T}$ depth distributions given in Fig. 7 for F82H. The figure also contains some literature data determined by a gas-driven permeation (GDP) by Serra ${ }^{21)}$ and Schliefer ${ }^{25}$ ) and a tritium desorption by Otsuka ${ }^{26}$. The latter two appreciably deviate downward from the extrapolation of the Serra's data in lower temperature range, while the present data are just on the extrapolation. This indicates that the present data are most likely corresponding to interstitial diffusion of $\mathrm{H}$ dissolved in $\mathrm{F} 82 \mathrm{H}$ within $20 \%$ of uncertainty.

As noted in Fig. 7, the experimental $\mathrm{H}$ depth distribution near surface region appreciably deviates from the analytical solution (eq. (4)) given as a dashed line. This is most likely caused by $\mathrm{H}$ release from the loaded surface during the cooling (around 1 minute) after termination of the loading. Assuming that $\mathrm{H}$ was released by diffusion for $1 \mathrm{~min}$ at the loading temperature just after termination of the loading, a depth distribution was numerically calculated by the $1 \mathrm{~d}$ diffusion analysis resulting in solid line in Fig. 7. Although the near surface concentration in the calculated distribution is less than the observed one, the maximum $\mathrm{H}$ concentration at the depth of $1 \mathrm{~mm}$ and the distribution in the $1-3 \mathrm{~mm}$ range represent well the observed one. The distribution in the deeper region was not subjected to change by the surface release, so as the diffusion coefficients determined from the depth distribution in the deeper region.

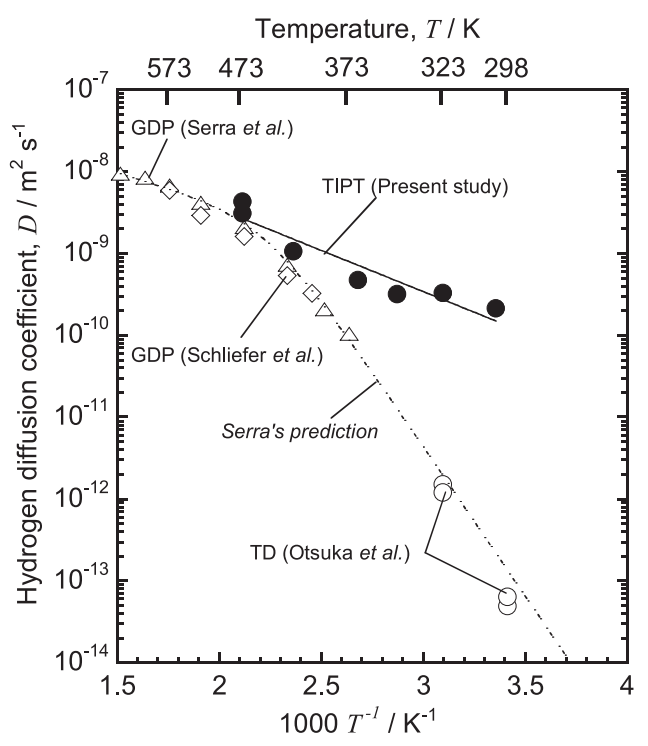

Fig. 10 Temperature dependence of $\mathrm{H}$ diffusion coefficients in the $\mathrm{F} 82 \mathrm{H}$ steel. Literature data determined by GDP by Serra ${ }^{21)}$ and Schliefer ${ }^{25)}$ and a tritium desorption by Otsuka ${ }^{26)}$ are also given for comparison.
The appearance of excess $\mathrm{H}$ (remaining $\mathrm{H}$ ) near surface region can be attributed to $\mathrm{H}$ trapped in the near surface region or $\mathrm{H}_{2} \mathrm{O}$ adsorbed at the surface, suggesting that the data deviating downwards in Fig. 10 are influenced by the surface $\mathrm{H}$ in determination of their diffusion coefficients. Because of its endothermic nature, dissolved $\mathrm{H}$ in $\mathrm{F} 82 \mathrm{H}$ should decrease exponentially with decreasing temperature, while the surface localized H stays rather constant. Hence, the deviation of the apparent diffusion coefficients become more appreciable at lower temperatures.

\subsubsection{H diffusion coefficients in pure $W$}

$\mathrm{H}$ diffusion coefficients in $\mathrm{W}$ are also determined with using the same $1 \mathrm{~d}$ diffusion analysis as $\mathrm{F} 82 \mathrm{H}$ from the T depth distributions beyond $0.5 \mathrm{~mm}$ in depth. In Figs. 8 (a) and (b) are plotted the $1 \mathrm{~d}$ analytical solutions showing the best fit to reproduce the observed distributions. Figure 11 shows temperature dependence of $\mathrm{H}$ diffusion coefficients in pure $\mathrm{W}$ thus determined. In the figure, literature data determined by GDP by Frauenfelder ${ }^{27)}$ and Zakhalov ${ }^{28)}$, an ion-driven permeation (IDP) by Nakamura ${ }^{29)}$, Lee ${ }^{30)}$ and Gasparyan ${ }^{31)}$, and a thermal desorption spectroscopy (TDS) by Esteban ${ }^{32)}$ and Franzen $^{33)}$ including our previous studies using TIPT ${ }^{11)}$, are also given for comparison. The data obtained by TIPT agree quite well with the extrapolated values of the Frauenfelder's data obtained above $1173 \mathrm{~K}$ to the present temperature range. Including the Frauenfelder's data, the Ikeda's data and the present data, a reliable set of diffusion coefficients of $\mathrm{H}$ interstitially dissolved in $\mathrm{W}$ is given by

$$
D=\left(3.8 \pm 0.4 \times 10^{-7}\right) \exp \left(\frac{-0.39 \pm 0.03[\mathrm{eV}]}{k_{B} T}\right),
$$

where $k_{B}$ is the Boltzman constant in $\mathrm{eV} \cdot \mathrm{K}^{-1}$, and $T$ is temperature in $\mathrm{K}$.

As seen in Figs. 8 (a) and (b), significantly large amount of $\mathrm{H}$ was retained in near surface regions at both the loaded

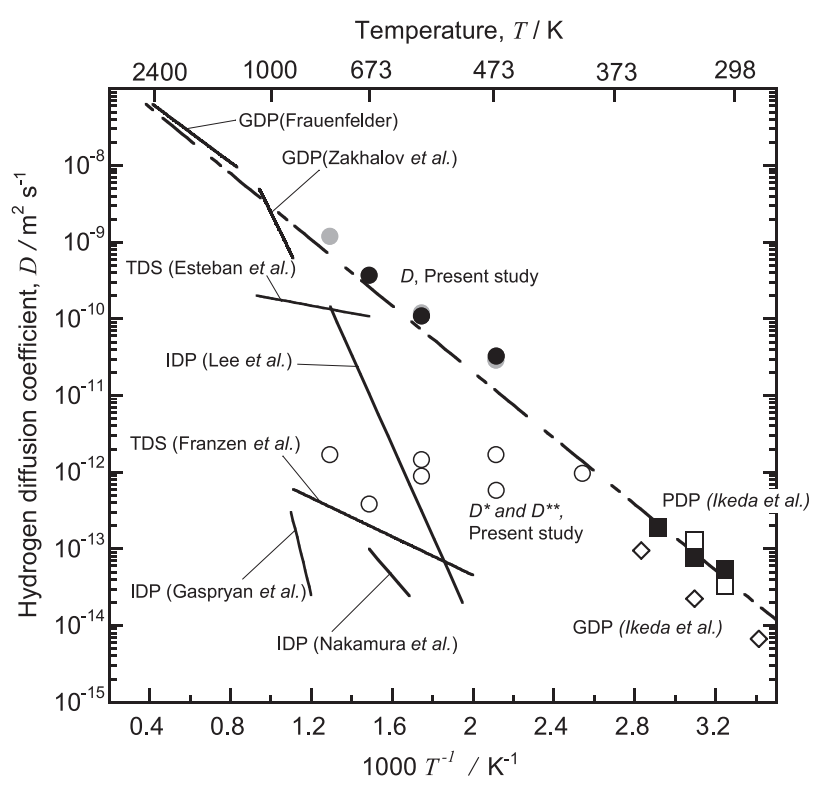

Fig. 11 Temperature dependence of $\mathrm{H}$ diffusion coefficients in pure W. Literature data determined by GDP by Frauenfelder ${ }^{27)}$ and Zakhalov ${ }^{28)}$, IDP by Nakamura ${ }^{29)}$, Lee ${ }^{30)}$ and Gasparyan ${ }^{31)}$, and TDS by Esteban ${ }^{32}$ ' and Franzen ${ }^{33)}$ are also shown. Data in our previous studies using TIPT $^{11)}$ are also plotted. 
surface and the opposite (back) surface compared to the amount of $\mathrm{H}$ retained in the deeper region. Assuming the decay of the near surface-localized component was also caused by diffusion, another set of diffusion data, $D^{*}$ and $D^{* *}$, were determined and plotted in Fig. 11. These diffusion data for the surface-localized components are roughly two orders of magnitude smaller than that for the interstitial diffusion $(D)$. In addition, their temperature dependence is quite weak. Therefore, we can conclude that the surface-localized component is strongly trapped.

It is important to note that the apparent diffusion coefficients determined from the surface-localized component are close to most of the literature data. Furthermore, the amount of $\mathrm{H}$ retained in the near surface region was much larger than that in the deeper region by orders of magnitude. If diffusion coefficients were determined by observation of $\mathrm{H}$ release, the values would correspond to the release of $\mathrm{H}$ retained in the near surface region, but not to $\mathrm{H}$ dissolved interstitially in the bulk. This suggests that most of the diffusion coefficients in previous works determined by release behaviors of $\mathrm{H}$ are not likely correspond to the bulk diffusion coefficients.

\subsection{Release behaviors of $H$ retained at surface, and in subsurface and bulk of metals}

Figure 12 compares calculated $\mathrm{H}$ depth distributions within $5 \mathrm{~mm}$ from the surface for $\mathrm{Zr}, \mathrm{Fe}$ and $\mathrm{W}$ with the loading by gas absorption at $13.3 \mathrm{kPa}$ and $573 \mathrm{~K}$ up to their solubility limits and followed $\mathrm{H}$ release afterwards for

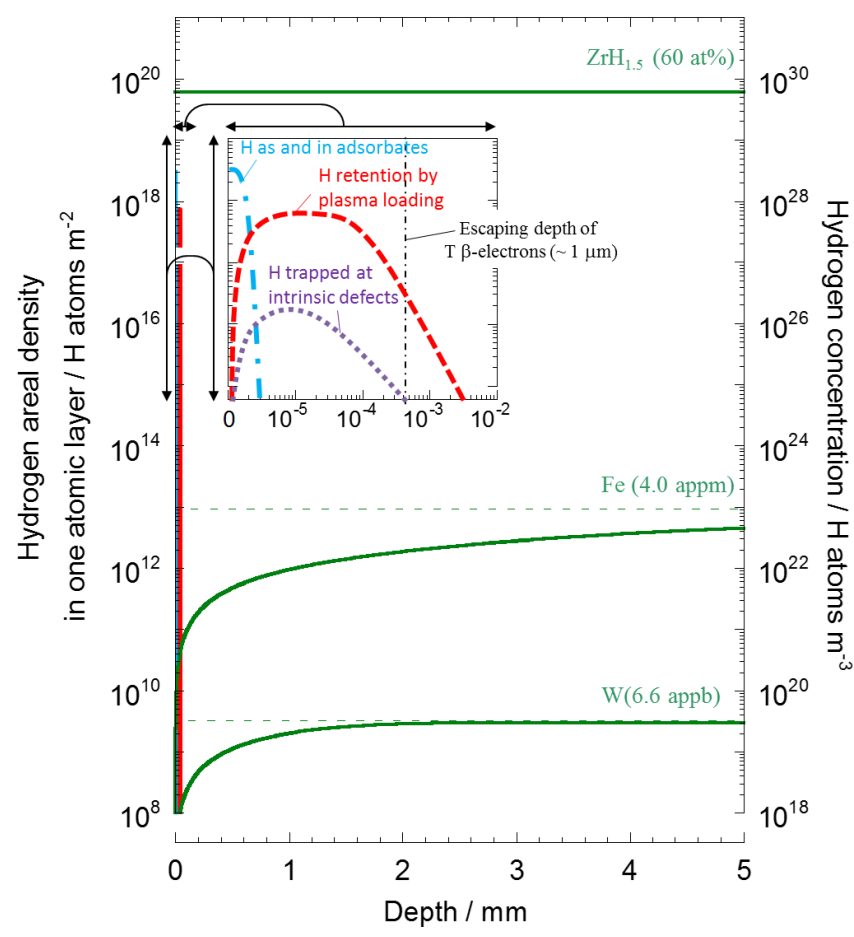

Fig. 12 Calculated $\mathrm{H}$ depth distributions within $5 \mathrm{~mm}$ for exothermic $(\mathrm{Zr})$ and endothermic $\mathrm{H}$ occluders ( $\mathrm{Fe}$ and $\mathrm{W}$ ) with $\mathrm{H}$ loading by gas absorption at $13.3 \mathrm{kPa}$ and $573 \mathrm{~K}$ upto their solubility limits and followed $\mathrm{H}$ release afterwards for $10 \mathrm{~min}$ at $573 \mathrm{~K}$. Surface localized components experimentally determined are separately given as an inset with enlarged vertical scales. Hydrogen concentration in vertical scale is given by both areal density in one atomic layer (thickness of $0.3 \mathrm{~nm}$ ) and volumetric concentration.
10 min at the same temperature. The calculation was made assuming diffusion controlled dissolution and release with diffusion coefficients expected form extrapolation of the reliable literature data obtained at higher temperatures ${ }^{27,34)}$ to $573 \mathrm{~K}$.

Owing to exothermic nature, $\mathrm{H}$ is not released from $\mathrm{Zr}$ keeping the original uniform distribution of zirconium hydride $\left(\mathrm{ZrH}_{1.5}\right)$, while in $\mathrm{Fe}$ and $\mathrm{W}$, the endothermic $\mathrm{H}$ occluding metals, appreciable amount of $\mathrm{H}$ once dissolved is released by diffusion showing the distribution decay from the deep inside to the surface. Actually, the decaying distributions in the deeper region of Fe and $\mathrm{W}$ obtained by TIPT agree well with the calculated $\mathrm{H}$ distributions to give reliable bulk diffusion coefficients.

At surface and in subsrface, depth distributions determined by TIPT, particularly for the endothermic occluders appreciably deviate from those of dissolved $\mathrm{H}$, as shown in the inset of Fig. 12. Within a few atomic layers of the surface including the top surface to a few $\mathrm{nm}$ in depth, there always exist adsorbed $\mathrm{H}$ atoms and/or $\mathrm{H}$ included in adsorbates such as ubiquitous water molecules (distribution given by a dashed and dotted line). Furthermore there could be chemically modified layers by impurities included in metals as often appearing as surface precipitates like oxide, carbide, nitride and some others, which also absorb $\mathrm{H}$. Beneath such the surface layers, $\mathrm{H}$ is rather densely trapped in various defects introduced by surface preparation such as cutting, grinding and polishing and also in the oxide layers (distribution given by a dotted line).

In case of plasma loading, there appears plasma-induced $\mathrm{H}$ saturated layers not only within a projection range of impinged ions or atoms but also spreading into $10 \mu \mathrm{m}$ in depth owing to excess loading of $\mathrm{H}$ from plasma ${ }^{11}$ (distribution given by a dashed line).

The significant $\mathrm{H}$ retention in the surface and subsurface is appreciable mainly in endothermic $\mathrm{H}$ occluders as depicted in the figure. $\mathrm{H}$ is chemically bound in the layers and hardly released at the loaded temperature. Integrated amount of $\mathrm{H}$ retained in the surface layers within a few $\mu \mathrm{m}$ is likely much larger than that of the dissolved H. Accordingly, diffusion coefficients determined by thermal desorption of the whole retained $\mathrm{H}$ or depth distributions in near surface regions could underestimate diffusion coefficients compared with those determined from $\mathrm{H}$ dissolved in bulk.

\section{Conclusions}

We have established TIPT as a new tool to observe depth distributions of $\mathrm{H}$ in metals with the cross-sectioning method. Owing to its very wide dynamic range for detection of $\mathrm{T}$ by TIPT, 4-5 digits, it gives quite detailed depth distributions of $\mathrm{H}$ in a metals from its top surface to deep inside (over $\mathrm{cm}$ range). Such detailed depth distribution allows us to separate $\mathrm{H}$ diffusive species from trapped ones and to determine reliable diffusion coefficients in metals having very low $\mathrm{H}$ solubility like $\mathrm{F} 82 \mathrm{H}$ and $\mathrm{W}$.

The depth distributions are quite different depending on heat of solution of $\mathrm{H}$ in metals, i.e. (1) endothermic or (2) exothermic: (1) High $\mathrm{H}$ concentration in exothermic $\mathrm{H}$ occluding metals hinders surface localized $\mathrm{H}$. Correspondingly 
the $\mathrm{H}$ depth distributions determined by the cross-sectioning method with TIPT well represents distributions of $\mathrm{H}$ dissolved or chemically bound to metal atoms (forming hydrides) in bulk. (2) In endothermic H occluding metals, the $\mathrm{H}$ depth distributions determined by the cross-sectioning method shows surface localization of $\mathrm{H}$ with quite tiny $\mathrm{H}$ dissolved in bulk. Because of endothermic nature with large $\mathrm{H}$ diffusion coefficients, $\mathrm{H}$ once occluded in the metals is desorbed via $\mathrm{H}$ diffusion in near surface regions. Accordingly, $\mathrm{H}$ remained in near surface region is limited to trapped ones or $\mathrm{H}$ with other different chemical forms. Moreover, owing to their low solubility, the amount of $\mathrm{H}$ or concentration of $\mathrm{H}$ in their bulk is quite small and only TIPT allows to observe. Although such near surface profiles of $\mathrm{H}$ can be obtained by ion beam analyses, their behavior does not correspond to that of $\mathrm{H}$ dissolved in bulk. Accordingly, apparent diffusion coefficients determined from the near surface profiles and/or their desorption might be different from bulk diffusion coefficients.

\section{Acknowledgement}

This work was supported by Grant-in-Aid for Scientific Research on Priority Area 467 "Tritium for Fusion" The Ministry of Education, Culture, Sports, Science and Technology (MEXT) No. 190550088, 20049006 and 22017005 .

\section{REFERENCES}

1) J. Völkl and G. Alefeld: Diffusion of hydrogen in metals, (SpringerVerlag, Berlin Heidelberg New York, 1978) pp. 321-348.

2) R.A. Causey: J. Nucl. Mater. 300 (2002) 91-117.

3) T. Tanabe, Y. Yamanishi and S. Imoto: J. Jpn. Inst. Metals 25 (1984) $1-10$.

4) K. Hashizume, M. Sugisaki, K. Hatano, T. Ohmori and K. Ogi: J. Nucl. Sci. Technol. 31 (1994) 1294-1300.

5) K. Fujii, K. Hashizume, Y. Hatano and M. Sugisaki: J. Alloy. Compd. 270 (1998) 42-46.

6) H. Saitoh, T. Misawa, Y. Noya and T. Ohnishi: Mater. Trans., JIM 40 (1999) 692-695.

7) H. Saitoh, H. Homma, T. Misawa and T. Ohnishi: Mater. Trans. 42 (2001) 399-402.

8) T. Hirano, Y. Saruwatari, K. Hashizume, T. Otsuka and T. Tanabe: Proc. E-MRS IUMRS ICEM 2006 (2006).
9) K. Hashizume, J. Masuda, T. Otsuka, T. Tanabe, Y. Hatano, Y. Nakamura, T. Nagasaka and T. Muroga: J. Nucl. Mater. 367-370 (2007) 876-881.

10) K. Hashizume, K. Ogushi, T. Otsuka and T. Tanabe: J. Nucl. Mater. 417 (2011) 1175-1178.

11) T. Otsuka, T. Hoshihira and T. Tanabe: Phys. Scr. T138 (2009) 014052 .

12) T. Otsuka and T. Tanabe: J. Alloy. Compd. 580 (2013) S44-S46.

13) M. Higaki, T. Otsuka, K. Tokunaga, K. Hashizume, K. Ezato, S. Suzuki, M. Enoeda and M. Akiba: Fus. Sci. Technol. 67 (2015) 379-381.

14) Y. Iwabuchi, N. Mori, K. Takahashi, T. Matsuda and S. Shionoya: Jpn J. Appl. Phys. 33 (1994) 178-185.

15) H. Ohuchi-Yoshida, Y. Hatano, Y. Kino and Y. Kondo: Fusion Eng. Des. 87 (2012) 423-426.

16) M. Matsuyama, T. Murai and K. Watanabe: Fus. Sci. Technol. 41 (2002) 505-509.

17) K. Sugiyama, T. Tanabe, K. Miyasaka, K. Masaki, K. Tobita, N. Miya, V. Philipps, M. Rubel, C.H. Skinner, C.A. Gentile, T. Saze and K. Nishizawa: J. Nucl. Mater. 329-333 (2004) 874-879.

18) M. Tamura, H. Hayakawa, M. Tanimura, A. Hishinuma and T. Kondo: J. Nucl. Mater. 141-143 (1986) 1067.

19) W.M. Robertson: Z. Metallk. 64 (1973) 436-443.

20) T. Tanabe, K. Sawada and S. Imoto: T. Jpn. I. Met. 27 (1986) $321-327$.

21) E. Serra, G. Benamati and O.V. Ogorodnikova: J. Nucl. Mater. 255 (1998) 105-115.

22) T. Sato, K. Niita, N. Matsuda, et al.: J. Nucl. Sci. Technol. 50 (2013) 913-923.

$23)$ P. C. Souers: Hydrogen properties for fusion energy, (University of California Press, Berkley and Los Angels, 1984) pp. 1-14.

24) T. Otsuka, M. Shimada, T. Tanabe and J.P. Sharpe: Fus. Sci. Technol. 60 (2011) 1539-1542.

25) F. Schliefer, C. Liu and P. Jung: J. Nucl. Mater. 283-287 (2000) 540-544.

26) T. Otsuka and T. Tanabe: Fus. Sci. Technol. 54 (2008) 541-544.

27) R. Frauenfelder: J. Vac. Sci. Technol. 6 (1969) 388-397.

28) A.P. Zakharov, V.M. Sharapov and E.I. Evko: Fiz. Khim. Mekh. Mater. 9 (1973) 29-33.

29) H. Nakamura, W. Shu, T. Hayashi and M. Nishi: J. Nucl. Mater. 313316 (2003) 679-684.

30) H.T. Lee, E. Markina, Y. Otsuka and Y. Ueda: Phys. Scri. T145 (2011) 014045 .

31) Y.M. Gasparyan, A.V. Golubeva, M. Mayer, A.A. Pisarev and J. Roth: J. Nucl. Mater. 390-391 (2009) 606-609.

32) G.A. Esteban, A. Perujo, L.A. Sedano and K. Douglas: J. Nucl. Mater. 295 (2001) 49-56.

33) P. Franzen, C. Garcia-Rosales, H. Plank and V.K. Alimov: J. Nucl. Mater. 241-243 (1997) 1082.

34) Y. Yamanishi, T. Tanabe and S. Imoto: T. Jpn. I. Met. 24 (1983) 49-58. 